\title{
Studying Labor Market Institutions in the Lab: Minimum Wages, Employment Protection and Workfare
}

\author{
Armin Falk \\ (IZA, University of Bonn, CEPR, CESifo) \\ David Huffman \\ (IZA)
}

\begin{abstract}
Understanding the interplay between institutions and labor markets is a central concern in economics. We argue that laboratory experiments are a powerful tool for studying labor market institutions, possessing several key advantages relative to more traditional approaches using field data. We exemplify the usefulness of lab experiments by surveying evidence from three studies, each of which investigates a different, crucial labor market institution: minimum wage laws, employment protection legislation and workfare.
\end{abstract}

We thank the German Science Foundation (DFG) for financial support through SPP1169 (Potential for more Flexibility on Heterogeneous Labor Markets). Corresponding author: Armin Falk. 


\section{Introduction}

Understanding the interplay between institutions and labor markets is a central concern in economics. We argue that laboratory experiments are a powerful tool for studying labor market institutions, possessing several key advantages relative to more traditional approaches using field data. This does not diminish the importance of field evidence, but rather shows that laboratory experiments are an important complement to these other types of methods. We exemplify the usefulness of lab experiments by surveying evidence from three studies, each of which investigates a different, crucial labor market institution: minimum wage laws, employment protection legislation and workfare.

The study on minimum wages offers an answer to two important puzzles in the minimum wage debate (for details, see Falk, Fehr and Zehnder (forthcoming)). The first concerns the so-called spill-over effect, i.e., the finding that firms respond to introduction of a minimum wage by paying wages even higher than the minimum, even though wages were below the minimum before the institutional change. For example, Card and Krueger (1995) and Katz and Krueger (1992) both find that fast food restaurants increased wages for workers by more than necessary, following an increase in the minimum wage. A second puzzle associate with minimum wages is the apparent reluctance of firms to pay wages below the minimum, even in cases where this is allowed. Katz and Krueger (1991, 1992), for example, show that the introduction of the opportunity to pay sub-minimum wages to youth had no discernible effect on teenage workers' wages. This underutilization of sub-minimum wages occurred even though the vast majority of firms paid a starting wage below the new hourly minimum immediately before it became effective. The Falk et al. experiment offers an explanation for both puzzles, centered on the interaction between minimum wage laws and workers' reservation wages. They show that the introduction of a minimum wage law changes what is considered a fair or acceptable wage by workers, thereby forcing firms to increase wages above the level of the minimum wage.

The second example investigates the economic consequences of employment protection legislation (EPL) in a competitive labor market with incomplete contracts (see Falk, Huffman and MacLeod, 2006). Theoretically, EPL could be either beneficial or harmful for labor market performance, and could help or harm the average worker by creating a wedge between outcomes of insiders and outsiders. The experiment by Falk et al. addresses three questions raised by these contrasting theoretical predictions. First, is the efficiency effect of EPL positive or negative, and is it large or small? Second, is the average worker 
better off under EPL? Third, how does EPL affect the types of contracts that are initiated, and how does it change the strategic nature of the contract enforcement problem? The first finding is that EPL has a significant but rather small negative impact on overall efficiency. Firms are substantially worse off under EPL, and workers are somewhat better off. What turns out to be crucial for preventing much more severe efficiency losses is the possibility for firms to condition payment on performance, e.g., by using bonus payments. Under EPL, contract terms change, featuring increased reliance on performance pay as opposed to efficiency wages. This restructuring of compensation is important for maintaining wellfunctioning employment relationships under EPL, because the threat of firing is eliminated. Falk et al. show that if firms are not allowed to pay bonuses, EPL is in fact much more harmful for firms, and overall efficiency of the market. This finding provides insights into the circumstances in which EPL performs well or performs poorly. In particular, the impact of EPL depends on the flexibility of contract forms allowed to firms, and on the extent to which firms can observe performance and reward or punish using contingent compensation.

The third paper discusses the pros and cons of workfare (see Falk, Huffman and Mierendorff, 2006). Unlike regular public assistance, workfare requires recipients to devote time to mandatory activities. This type of program has been introduced in several European countries as well as in several states of the US. The workfare experiment by Falk, Huffman and Mierendorff studies two of the most important and discussed issues of workfare. First, does workfare increase employment via a downward shift of labor supply? This is predicted by economic theory because the work obligation reduces the relative attractiveness of being on public assistance. The second issue is concerned with the public support of workfare. This question is crucial insofar as in democracies public support is a prerequisite for the introduction of institutions. In the experiment subjects engage in a paid real effort task. Their individual supply curves are elicited in an incentive compatible way. As predicted by economic theory these supply curves are shifted downward in the presence of workfare, establishing a positive incentive effect of workfare. In a second experiment subjects can vote in favor or against workfare, prior to knowing whether they personally will be affected by this rule. In this setting, there turns out to be tremendous support for workfare. The experiment shows that the motives behind this support are partly self-interested, but that workfare is also perceived as fair, in the sense that it punishes free riders.

These three studies illustrate how experiments can serve as a valuable complement to field data for the purpose of studying labor market institutions. First, in all experiments institutions are exogenously changed. This exogeneity is perhaps the most important 
advantage of laboratory experiments for studying the economic effects of institutions. For example, in the case of an institution such as the minimum wage, an experiment makes it possible to observe a labor market before the minim wage is introduced, and then after it has been imposed exogenously, holding everything else constant. In the field, by contrast, institutions such as minimum wage laws, employment protection or workfare are adopted endogenously. Governments choose institutions in response to current or anticipated economic and political conditions in the market. This makes causal inferences difficult (Besley and Coate, 1999). Econometric strategies such as instrumenting for policy changes with political variables can help ameliorate this problem, but do not achieve the unequivocal exogenous variation provided by a laboratory experiment. For interpreting the impact of EPL, or workfare, exogeneity is similarly important.

Another key advantage of laboratory experiments is the unparalleled opportunity to control crucial aspects of the economic environment. This includes control over information conditions, technology, market structure, and trends in economic fundamentals. Control helps dealing with important challenges arising in the study of institutions, for example, the difficulty of disentangling the impact of a change in institutions from changes in other, confounding time trends. In the field, controlling for such time trends requires identifying a plausible control group, whereas in an experiment it is possible to rule out such time trends by design. Laboratory experiments also make it possible to observe the impact of institutions on behavior at the level of individual economic agents. This is important given that theoretical predictions regarding the impact of institutions typically involve such micro behaviors. For example, an institution such as employment protection legislation (EPL) changes the strategic position of firms and workers, and thus is predicted to alter various aspects of contract initiation, and contract enforcement in the labor market. It is through these channels that EPL is then predicted to have an impact on efficiency and distribution at the aggregate level. In an experimental labor market it is possible to observe these behaviors directly, and thus test the theoretical predictions. In field data, changes in micro behavior must typically be inferred from changes in aggregate outcomes. Another example is minimum wages, where the precise observation of reservation wages is crucial. While in the lab these can be observed with little or no measurement error, they are hardly ever observable with field data. Finally, the impact of an institution such as workfare depends on how it shifts individual labor supply curves. In an experiment it is possible to directly elicit individual labor supply curves, in an incentive compatible way, using a real effort task. In the field it is always necessary to estimate supply curves. 
Control over the decision environment also makes it possible to identify the theoretical equilibrium in an experimental labor market. In the field, the equilibrium is never similarly clear. Knowing the equilibrium has important advantages, both for evaluating the efficiency consequences of an institutional change, and for knowing whether observed behavior can be expected to be stable. Because the equilibrium is known, it is also possible to use laboratory experiments to study the impact of institutions on the convergence properties of markets. With laboratory experiments one can also study institutions that do not yet exist, at relatively low cost. Analogous to experimental tests of new medicines, where the medication is administered to a small subset of the population initially, laboratory experiments can be used as a first step, before experimenting with institutions in the field. Importantly, the costs of testing institutions in the field can be greater than just the costs building political support and paying for administration of the experiment. Some institutional changes can have lasting effects, even after they have been removed. This potential irreversibility is illustrated in our experimental study of minimum wage laws where reservation wages increase when a minimum wage is introduced, and remain high even after the minimum wage is removed once again.

Although we believe that laboratory experiments offer important advantages for studying institutions, and should thus be exploited more often, it is important to recognize that there are also drawbacks to this method, which make field evidence indispensable. A key disadvantage is potentially limited generalizability. ${ }^{1}$ Note, however, that this critique holds with respect to any data set, given that any empirical observation is time and space contingent. Another concern often raised is that experiments may be too simple, missing important aspects, which could also be relevant. This is in fact both a problem and an advantage of experiments. Just as economic models are simpler than reality, so experiments are designed to simplify as much as possible, without losing the essentials. Thus, simplicity need not be a defect of an experiment. The key challenge, just as in the case of building economic models, is to include those features that are essential to the question at hand.

The rest of the paper is organized as follows. Section 2 illustrates the power of the experimental approach by survey results from a study of minimum wage laws. Section 3 surveys evidence from an experiment that investigates the impact of EPL on the labor market.

\footnotetext{
${ }^{1}$ For example, laboratory experiments are often criticized for using students as subjects and paying only small stakes. This is not a fundamental objection to the use of experiments, because it is possible to use non-student subjects and pay high amounts of money, and in fact this is becoming increasingly common.
} 
Section 4 discusses a study on the incentive affects, and political acceptability, of a workfare institution. Section 5 concludes.

\section{Minimum Wage Laws}

The minimum wage is a particularly important labor market institution. In fact, most markets in the developed world are affected by minimum wage legislations in one way or the other. ${ }^{2}$ Not surprisingly therefore, numerous empirical studies have investigated the economic effects of minimum wages. Despite much progress, however, several important puzzles remain.

In their laboratory experiment on the effects of minimum wages Falk, Fehr and Zehnder (forthcoming) analyze two of these unsolved puzzles. The first is the so-called spillover effect, i.e., the fact that after an increase in the minimum wage, firms often increase wages by an amount exceeding that necessary to comply with the higher minimum wage (see, e.g., Card and Krueger 1995, Katz and Krueger 1992). The second is the finding that firms often do not take advantage of opportunities to pay sub-minimum wages, even when they are explicitly allowed to do so, and even though they paid less than the minimum before the minimum wage was introduced (see, e.g., Katz and Krueger 1991, 1992). The experiment provides a parsimonious explanation for both of these puzzles that hinges on the effect of minimum wages on workers' reservation wages. Since with field data reservation wages are typically unknown to the researcher, the experiment neatly demonstrates the power of the laboratory for studying this institution.

In their experiment Falk et al. study a stylized labor market in which a firm can hire up to three workers. Firms have identical production functions with labor as the only variable input and decreasing marginal returns. To hire workers, firms submit a unitary wage offer to each of the three workers. Before they know which wage offer they actually get, workers indicate their reservation wage, i.e., the lowest wage they are just willing to accept. If the received wage offer is lower than the worker's reservation wage it is automatically rejected, otherwise it is accepted. Upon acceptance a binding and complete labor contract is concluded, i.e., the worker receives the wage and the firm's output increases. Firms' payoffs

\footnotetext{
${ }^{2}$ National or statutory minimum wages exist in 19 OECD countries, and in at least 6 more OECD countries minimum wages are effectively set through collective agreements (National or Statutory Minimum Wages: USA, Canada, Japan, UK, Belgium, France, Czech Republic, Greece, Hungary, Korea, Luxembourg, Mexico, Netherlands, New Zealand, Poland, Portugal, Spain, Turkey, Ireland. Collective Agreements: Germany, Austria, Sweden, Denmark, Finland, Italy). For detailed information see OECD (1998).
} 
are given by total output minus wages. To study the economic effects of minimum wages Falk et al. study two treatments, one with and one without a minimum wage. They also study two treatment orders, one where a minimum wage is introduced and one where a minimum wage is removed. ${ }^{3}$

The main results of their study are summarized in the following. First, there is evidence of a spill-over effect, similar to that found in empirical studies mentioned above: in the absence of a minimum wage law the vast majority of wages is below the minimum wage level; after the introduction of the minimum wage, the majority of actual wages is not just raised to the level of the minimum wage but above that level. This spill-over effect is shown in Figure 1, which is a histogram of all wages paid to workers. These include wages paid in the absence of a minimum wage (grey bars) as well wages as in the presence of a minimum wage (black bars). Wages are in between 0 and about 300 and the minimum wage (MW) was set equal to 220 in the experiment.

Figure 1 about here

As is obvious from this figure, wages after the introduction of the minimum wage are not only substantially higher than before the introduction, but also much higher than the level of the minimum wage. With a minimum wage in place, only seven percent of all wages are exactly at the level of the minimum wage while 93 percent of the wages are higher than 220 . This strong spill-over effect of minimum wages is remarkable insofar as prior to the introduction of the minimum wage only 8 percent of the wages were above 220 . Put differently, while 92 percent of the wages were below 220 before the introduction of the minimum wage, firms now pay wages above 220 in 93 percent of the cases.

An explanation for the spill-over effect is given in the second main result and has to do with workers' reservation wages. In the absence of the minimum wage law individual reservation wages are almost all below the minimum wage level. However, in the presence of the minimum wage law a large share of the subjects exhibit reservation wages above the minimum wage level. Reservation wages are displayed in Figure 2, which shows a histogram of stated reservation wages in the condition without minimum wages (grey bars) and the condition with minimum wages (black bars). Figure 2 reveals that in the absence of minimum

\footnotetext{
${ }^{3}$ In each of the ten sessions there were 24 subjects (six firms and eighteen workers), yielding a total of 240 participants in the experiment. A session lasted approximately two hours and subjects earned on average 49 Swiss Francs (CHF $49 \sim$ US \$ 40).
} 
wages only 9 percent are equal or higher than the level of the later introduced minimum wage. After the introduction of the minimum wage, however, 49 percent of reservation wages are above the minimum wage level. Thus, many workers who were willing to accept wages below the minimum wage level in the absence of a minimum wage institution state reservation wages above the minimum after the introduction of the minimum wage. Clearly, the higher level of the reservation wages after the introduction of the minimum wage force firms to pay wages above the minimum wage level. Thus, reservation wages provide a plausible explanation for the observed spill-over effect.

The experiment suggests that minimum wages systematically affect what is considered a fair wage. Wages that were considered acceptable in the absence of a minimum wage are now perceived as relatively low and unfair and are therefore no longer accepted. ${ }^{4}$ This is actually how Card and Krueger interpret their findings: "the minimum wage becomes a focal point, representing the going, or acceptable wage. [...] workers perceive the minimum wage as the "fair" wage. In this way, the minimum wage might influence workers' reservation wages." (p. 159). Of course, Card and Krueger can only speculate about the role of reservation wages, given that they observe only aggregate outcomes. In the experiment under discussion, by contrast, it is possible to make a precise statement on the basis of directly observable reservation wages.

Figure 2 about here

Falk et al. also study the removal of a minimum wages. According to standard economic wisdom the effect should be perfectly symmetric with respect to introduction of a minimum wage, given that the institutional rules and therefore the economic incentives people face are exactly the same. We would therefore expect that the effects on wages and reservation wages are exactly the same independent of the treatment order, i.e., that removing the minimum wage lowers wages significantly. Moreover one would expect that the effects are similar in size compared to the introduction of a minimum wage. This, however, is not the case: the temporary introduction of the minimum wage has permanent effects on actual wages, i.e.,

\footnotetext{
${ }^{4}$ A plausible explanation for this finding can be given in terms of fairness intentions. From several experiments it is known that the same payoff distribution is perceived differently depending on the underlying fairness intentions (e.g., Blount 1995, Falk et al. 2003). In line with this argument Brandts and Charness (2004) show that workers provide less effort for the same wage level in the presence of the minimum wage, lending support to the view that workers' effort responses are partly shaped by fairness attributions.
} 
even after the removal of the minimum wage actual wages stay close to the previous minimum wage level. Thus, a pre-minimum wage economy exhibits significantly different wages compared to a post-minimum wage economy although the two economies are identical in all exogenous parameters. To see this we show in Figure 3 average wages over time for both treatments and sequences. Wages in the presence of a minimum wage are very similar, independent of whether a minimum wage was introduced or removed. ${ }^{5}$ When we look at wages in the absence of minimum wage legislation, however, wages differ substantially. Prior to the introduction of a minimum wage average wages are much lower than after the removal of the minimum wage legislation. This means that wages are strongly affected by the experience of such an institution.

Figure 3 about here

The explanation for higher wage levels is again differences in the reservation wages. After the removal of minimum wage legislation reservation wages are much higher than before its introduction. As a consequence, firms are forced to pay relatively high wages even though the legal obligation is absent. This observation is relevant for explaining the second puzzle, the anomalously low utilization of sub-minimum wages in situations where firms actually have the possibility to pay workers below the minimum.

One plausible explanation for why reservation wages stay high even after the removal of the minimum wage legislation is a so-called entitlement effect. Schlicht (1984) defines entitlements as "rights, as perceived by the individual. They are not, however, legal rights. Rather they denote the subjectively perceived rights that go along with a motivational disposition to defend them" (p. 24). Important sources for the formation of entitlements are past allocations, which results in a "sense of ownership in the status quo" (Zajac, 1995, p. 121). In the case of minimum wage legislation it is likely that workers who have been exposed to relatively high minimum wages get used to receiving such wages, and thus feel they have a right to being offered high wages even after the minimum wage law has been removed.

Taken together the Falk et al. paper shows that minimum wages affect reservation wages in a complex way, giving rise to spill-over effects as well as the anomalously low

\footnotetext{
${ }^{5}$ This also shows that the spill-over effect shows up regardless of whether we introduce the minimum wage at the beginning of the experiment or after subjects experienced an economy without the minimum wage.
} 
utilization of sub-minimum wages. ${ }^{6}$ The identification of these effects rests on two important features that are available in the lab but hard to get with field data. The first is the direct observation of reservation wages, which are typically not available in field data sets. The second feature concerns the ceteris paribus comparison of a labor market with and without minimum wages as well as the possibility to study asymmetric effects concerning the introduction and removal of institutions. The observed asymmetries challenge the standard economic perspective, which suggests that behavior is solely driven by the set of economic incentives.

\section{Employment Protection Legislation}

EPL is another important labor market institution that affects a large number of countries (see OECD, 1999). EPL refers generally to rules or legislation that limit the ability of an employer to dismiss a worker. Theoretically, EPL is a two-edged sword, both in terms of redistribution and efficiency. On the one hand it protects employed workers from dismissal without cause. On the other hand, it may make firms more reluctant to hire new workers (Autor et al., 2004). In terms of efficiency, EPL could be beneficial, in the context of a gift-exchange relationship: by providing a credible commitment to greater job security, EPL may allow firms to offer lower wages without a reduction in effort on the part of workers (MacLeod, 2005). EPL could also be a serious drag on efficiency, however, by preventing the breakup of bad matches, and by eliminating the threat of firing as a tool discouraging workers from shirking (Epstein, 1984).

Field evidence on EPL has mainly exploited variation in the strictness of EPL across countries or states, and studied the correlation with unemployment levels. Overall, findings show a weak relationship, if at all (see Nickell, 1997 for a review). There is also some field evidence on the impact of EPL on labor turnover. Consistent with EPL making firms reluctant to hire new workers, countries with more stringent EPL experience lower labor turnover, and lower exit rates out of unemployment (Kugler and Saint-Paul, 2000). This

\footnotetext{
6 They also show that due to the monopsonistic structure of their labor market, the employment effects of minimum wages are actually positive. These findings speak to a third puzzle: The new minimum wage research in the 1990s (Card 1992; Card and Krueger 1994, Katz and Krueger 1992, Machin and Manning 1994) has questioned the conventional wisdom that increases in the legal minimum wage always cause a decrease in employment. These results are contested (see, e.g., Neumark and Wascher 1992 and 2000; Card, Katz and Krueger 1994; Card and Krueger 2000) but they nevertheless constitute a considerable challenge to the conventional view of the employment effects of minimum wages.
} 
evidence constitutes substantial progress, but some of the most fundamental questions surrounding EPL remain unanswered. This gap is presumably due, at least in part, to the fact that these questions are very difficult to answer in the field.

Falk, Huffman, and MacLeod (2006) conduct an experiment designed to address three important unanswered questions regarding EPL. First, is the overall impact of EPL on efficiency positive or negative, and is the effect is large or small? Second, does EPL make the average worker better off? Third, how does EPL affect behavior at the micro level, in terms of contract terms, the strategies of firms in hiring new workers, and the nature of the strategic interaction between workers and firms in long-term relationships? There are several reasons why an experiment is a useful technique for answering these questions. First, it is possible to observe two labor markets that are identical, except that one includes an EPL institution and the other does not. These are the ideal conditions for drawing causal inferences about the impact of EPL, and avoid numerous potential confounds. E.g., if EPL were instead adopted endogenously, in markets where workers tend to fare poorly, this could lead to a downwardbiased or negative relationship between worker outcomes and the presence of EPL. An experiment also makes it possible to study the impact on market efficiency, and distribution of rents between workers and firms, because these variables can be measured precisely. In the field a key obstacle is that efficiency and distribution are very difficult or impossible to measure. Finally, an experiment can make transparent the impact of EPL at a level of detail that is not possible in the field, including the effort decisions of individual workers, and the individual contract offers of firms, even those that are not accepted. This window into behavior at the micro level is particularly valuable, given that theories regarding the impact of EPL start from assumptions about micro level behaviors, which are difficult to test using field data.

In the experiment there were 18 trading periods. A firm could hire one worker per period and a worker could accept a maximum of one job in a period. Each trading period had three stages. First, there was a market phase, where firms offered contracts and workers made decisions whether to accept or not to accept. Second, if a firm and worker agreed on a contract, they entered a second phase, in which the worker chose the effort level. Third, the firm and worker entered a phase where the firm is informed about the effort choice of the worker, and then has the choice of how much of a bonus to pay. Importantly, the worker's effort level and the firm's bonus payment were not enforceable.

Firms were always the contract makers. A contract consisted of a wage, a desired effort, and an offered bonus. Firms could make a public offer, available to all workers on the 
market, or could make a private offer, available only to a specific worker, identified by the worker's ID number. Firms could make as many offers as they wanted during the duration of the market phase. Once one offer was accepted, a firm's other offers were removed from the market. Firms knew which workers were still on the market at any given point during the market phase. In every session, there were 7 firms and 10 workers. Workers who did not find an employer in a given period earned a small benefit representing the outside option.

In one treatment the labor market experiment was run with the institutions as described above. In a second treatment, EPL was added to the market, in the following form: if a firm made a private offer to the same worker for two periods in a row, and the worker accepted both times, then the firm was no longer able to dismiss the worker. Instead, the firm was required to make an offer to the worker, in a phase occurring before the market phase of the next period. Importantly, the offered wage was required to be at least as high as the period in which the EPL relationship was formed. This rigidity in wages prevents a firm from forcing a worker protected by EPL to quit, by lowering the wage to zero. After the EPL offer phase, the market phase began as usual. Workers on EPL could see their firm's offer, but also all other offers being made on the market. At any time, the worker could accept the EPL offer, or could reject the offer by accepting another offer on the market. As long as the worker continued to accept a firm's EPL offers, the firm was required to make a new offer in each subsequent period, until the end of the game. Once the worker rejected the offer, the EPL relationship was at an end, and the firm was free to make offers to other workers during the remainder of the market phase for that period, and in subsequent periods. ${ }^{7}$

The first main finding is that EPL has a significant but rather small impact on aggregate efficiency in the labor market. Averaged across sessions, total economic surplus is 69 percent of maximum in the market without EPL, and 62 percent of maximum in the labor market with EPL. The fact that the drop is relatively small (9 percent) is in some sense consistent with the weak effects observed using field data, although measures of efficiency are less precise in the field. A more detailed analysis of strategic behavior within employment relationships, discussed below, provides some insights into why and under what circumstances EPL may have only a mild impact on efficiency. The second main finding regards the impact of EPL on the distribution of rents between workers and firms. Firms are

\footnotetext{
${ }^{7}$ There were 12 sessions, 6 for each treatment, for a total of 204 subjects. Subjects were students at the University of Bonn. On average sessions lasted 2 hours, and subjects earned 25 Euros.
} 
substantially worse off in a market with EPL (average profits are roughly 21 percent lower), and on average, workers are somewhat better off (utility is roughly 8 percent higher).

Because behavior is observable at the level of individual economic agents, it is possible to investigate channels operating at the micro level that lead to these aggregate outcomes. One finding is that firms are more reluctant to enter long-term relationships in the market with EPL. This can be seen in a Probit regression where the dependent variable is equal to 1 if a firm makes a private offer to a worker $i$ for a second time in a row, and 0 otherwise. Independent variables include a treatment dummy, and firm profits in the previous period. The treatment dummy is negative and significant, indicating that the EPL institution makes firms less likely to make a second private offer to the same worker, conditional on previous period profits. This higher threshold for relationship formation is consistent with firms being concerned about the possibility of entering an EPL relationship and then being stuck with a worker who shirks every period. Note that the exogenous implementation of EPL is particularly useful, because otherwise there would be an alternative interpretation, where governments adopt EPL precisely because firms are reluctant to maintain long-term relationships. The greater reluctance to form relationships in the market with EPL is one source of inefficiency, because EPL relationships are significantly more efficient (effort levels are higher) than in public-offer relationships.

EPL also leads to inefficiency by changing the behavior of workers in long-term relationships. In the market with EPL, a worker and firm end up in a long-term relationship after two private offers, and then only workers can terminate the relationship. In the market without EPL, many firms and workers end up in long-term relationships, where a firm makes a private offer each period to the same worker and the worker accepts. In this case, however, either the firm or the worker can end such a relationship (for previous evidence on endogenous long-term relations, see Brown, Falk, and Fehr, 2004). It turns out that effort levels in EPL relationships are significantly lower than effort levels observed in long-term relationships without EPL, making EPL relationships less efficient. ${ }^{8}$ Notably, effort levels are never observable in the field. This effect can be seen in an OLS regression of effort on contract terms (wage and offered bonus) and a treatment dummy, where the sample is restricted to EPL relationships or long-term relationships (2 or more private offers in a row) in the market without EPL. The treatment dummy is negative and significant, indicating that

\footnotetext{
${ }^{8}$ Given the parameters of the experiment, efficiency is always increasing in the effort level: the marginal benefit of effort to firms is always higher than the marginal cost to workers. This implies that the maximum level of effort, 10, is the most efficient level.
} 
workers put in less effort for the same compensation in EPL relationships. Lower effort levels under EPL clearly reflect the change in strategic positions of workers and firms, namely the inability of firms to fire the worker. The treatment without EPL provides the relevant counterfactual, showing what would happen if firms were able to fire workers. Long-term relationships without EPL are very unlikely to continue if the firm earned low profits in the previous period, breaking up with probability close to 1. Overall, long-term relationships continue in only about 30 percent of all cases. In EPL relationships, however, firms earn substantially lower profits, but at the same time relationships are terminated (by workers) in only 2 percent of all cases. This is understandable given that workers achieve higher utility in EPL relationships on average, compared to long-term relationships without EPL.

Although EPL reduces efficiency, the impact is relatively small. Looking at the impact of EPL on contract terms provides some insight as to why this is the case. Wage offers are very similar, but offered bonuses are substantially higher, in EPL relationships compared to long-term relationships without EPL. One explanation is that firms make more extensive use of the bonus option in EPL relationships, to make up for the lack of threat of firing as an incentive device. ${ }^{9}$ This suggests one reason why the impact of EPL on efficiency is small when comparing the two treatments, and raises the possibility that the damage to efficiency might be much larger in the absence of the ability to pay bonuses. In order to test this hypothesis, Falk, Huffman, and MacLeod (2006) conducted a third treatment that included EPL, but did not allow firms to pay bonuses. Figure 4 shows a powerful confirmation of the hypothesis. Effort levels (equivalently, efficiency) are about 9 percent lower in EPL relationships with bonuses, compared to the long-term relationships without EPL. Effort is 41 percent lower, however, in the EPL market where firms are not allowed the flexibility to condition payment on performance. An important implication is that the impact of EPL may vary across countries and markets, depending on the flexibility of a country's legislation regarding acceptable contract forms, and on the ability of firms in particular industries to link pay to performance.

Figure 4 about here

In summary, the experiment provides sharp answers, and generates new insights, regarding some of the most important questions surrounding EPL. In particular, the impact of

\footnotetext{
${ }^{9}$ This is in line with the theoretical predictions of MacLeod (2005).
} 
EPL on efficiency is clearly negative, and workers are made better off at the expense of firms. However, these outcomes depend on how EPL affects the strategic nature of the employment relation. To the extent that firms are unable to use other incentive devices to compensate for their weak position in terms of being unable to dismiss workers, EPL may have much more severe. reduces efficiency, but by a relatively small amount if firms have other ways to reward or punish workers besides the threat of firing. This illustrates the value of the experimental approach, given that these questions are typically impossible to answer using field data. The experimental framework is also a potential platform for future research on EPL. One example of an interesting extension would be to explore the impact of longer probation periods leading to EPL. There could be non-linear effects, which are important to take into account when constructing EPL institutions.

\section{Workfare}

Workfare programs have been introduced in several European countries and are a subject of public debate in others. Unlike regular public assistance, workfare requires recipients to spend some time on mandatory activities such as community work, job training, etc. Economic theory predicts that workfare can increase the incentive for benefit recipients to seek regular employment, because the work requirement reduces the attractiveness of being on public assistance. Taxpayers might support workfare for this reason, but there could be other reasons why people support or oppose workfare.

A study by Falk, Huffman, and Mierendorff (2006) uses laboratory experiments to investigate two of the most important and discussed issues surrounding workfare. First, does workfare increase employment via a downward shift in labor supply? This is the prediction of economic theory, because the work requirement decreases the attractiveness of remaining on public assistance. Second, how strong is political support for workfare, and what are the motivations behind this support? In particular, it is interesting to investigate whether workfare is perceived as unfair, generating opposition to the institution, or whether fairness considerations reinforce political support for workfare. Answering these questions is crucial for assessing the likelihood that workfare is politically viable, and for understanding the circumstances that increase or decrease political support.

Experiments are a useful complement to field evidence in this case, for several reasons. Economic theory predicts that workfare affects individual supply curves, but in the field supply curves are never observed and must always be estimated. In their experiments 
Falk et al. show how it is possible to elicit an individual's supply curve directly, in an incentive compatible way. One criticism of laboratory experiments is that effort choices often consist of choosing a number, rather than exerting real effort. However, the authors address this criticism by eliciting supply curves for a task involving real effort. The experiments also offer advantages in terms of understanding political support for workfare. It is possible to observe actual voting decisions in the experiments, with real earnings and real effort at stake, and to elicit detailed information about the motivations behind these decisions. It is also possible to minimize confounding heterogeneity in beliefs. For example, support for workfare may depend on an individual's beliefs about many different details of the economy and institutions, which are difficult to control for completely using only field data. In the experiments by Falk et al., the functioning of the voting institution, and the choice problem facing all participants, are made common knowledge. Finally, an experiment makes it possible to study political support for workfare in an environment where voters do not know their position in society, which is not possible in field studies. This is potentially valuable for understanding whether workfare is considered fair, in the sense that it would be chosen behind a Rawlsian "veil of ignorance."

In their first experiment, Falk, Huffman, and Mierendorff (2006) investigated the incentive effects of attaching a work requirement to public assistance, where the work requirement took the form of a real-effort task. The task was designed to be unproductive, and to impose pure disutility; one unit of the task involved counting the numbers of zeros on a sheet of paper printed with a block of random zeros and ones. After a trial phase in which they experienced the task, subjects filled in a series of choice tables in random order. Each row in a given table offered a choice between two different payments for two different quantities of the work task. Subjects knew that one row from one table would be randomly selected, and that their choice in this row would determine how many sheets they had to do in order to receive the associated fixed payment. ${ }^{10}$ This method ensured that stated preferences were incentive compatible. Importantly, subjects also knew when they made their choices that they would be paid and allowed to leave the laboratory as soon as they had completed their work task. For example, a subject choosing the option 4 Euros for 0 sheets would be paid and allowed to leave the lab immediately after the work phase began. This design helps ensure that subjects

\footnotetext{
${ }^{10}$ Subjects knew that they had to answer the chosen number of sheets correctly in order to receive the payment. They had three tries to enter the correct answer for a sheet into the computer, before having to move to the next one. They were allowed a maximum of 20 sheets.
} 
face real tradeoffs between income and leisure time.

The choice tables were constructed to elicit two supply curves for each individual. For example, in one table each row involved a choice between 4 Euros for 0 sheets and X Euros for 5 sheets. Moving down the table, the amount X increased from 0 to 9 Euros, in steps of 1 Euro. The amount $\mathrm{X}$ needed to induce the individual to switch from the outside option of doing 0 sheets for 4 Euros (welfare) to doing 5 sheets (regular employment) gives one point on the individual's supply curve. Another table, which was the same except that regular employment involved 10 sheets, gives a second point on the supply curve. Two more tables were used to elicit the individual's supply curve when the outside option was 4 Euros but also involved a work requirement of 9 sheets (workfare). ${ }^{11}$

The main finding from the first experiment is illustrated in Figure 5. On average, supply curves are upward sloping, and the presence of a work requirement in the outside option causes an individual's supply curve to shift down. This supports the hypothesis that workfare increases the likelihood that participants seek out regular employment, by reducing the value of the outside option and shifting supply curves downward.

Figure 5 about here

In a second experiment with different subjects, Falk, Huffman, and Mierendorff (2006) had subjects interact anonymously in groups of three. Two of the group members were required to work for a fixed wage. The work task was the same as in the first experiment. The third person in each group decided whether to work like the others, or not to work and receive a transfer taken from the earnings of other group members. By claiming the transfer, a recipient created a negative externality for the other group members. Before knowing their roles, all group members voted on whether to introduce a work requirement for transfer recipients. After voting, potential recipients learned the outcome of the vote, and could decide whether to work or to receive a transfer. Then all subjects answered a questionnaire, and performed their assigned amounts of the work task. Importantly, subjects could leave immediately once they were done with the questionnaire, if they had no work requirement, or as soon as they were done with their required units if they did have to work. This was

\footnotetext{
${ }^{11}$ There were 3 session for the experiment, lasting on average 90 minutes, for a total of 55 subjects. Subjects were students at the University of Bonn. On average subjects earned about 16 Euros.
} 
common knowledge when subjects voted. ${ }^{12}$

The first main finding is that roughly 84 percent of the subjects vote for the imposition of a work requirement. This raises the question of why workfare is so popular. The questionnaire following the experiment asked open-ended questions about subjects' motivation for voting for workfare. In most cases it is possible to classify these responses into one of several distinct groups. Figure 6 shows the results of this classification. Roughly 16 percent of those who voted for workfare are express motives that are purely self-interested. Their reason for supporting workfare was to encourage the recipient to choose regular employment, thereby avoiding the cost of paying a transfer in the likely case that they themselves end up in the role of a worker. On the other hand, 56 percent of subjects have motivations that are primarily social, in the sense that they only mention terms such as fairness, social norms, or a desire to punish free riders, as the motivation for supporting workfare. 15 percent mention both types of motivation. The remaining subjects have other motivations, or support welfare rather than workfare. These findings suggest a reason why workfare may be strongly supported politically: in the setting off the experiment, workfare appeals both to those who are mainly self-interested, and to those who are socially motivated. This finding is relevant for political debates on the fairness of workfare, showing that in these circumstances workfare is indeed perceived as fair.

Figure 6 about here

A final result concerns the behavior of subjects in the role of recipient. Looking at the choice between regular employment, and participating in workfare, it turns out that workfare take-up is significantly lower in the second experiment, where workfare imposes a negative externality, compared to the first experiment where no externality was created by choosing the workfare option. This suggests that people are more likely to choose regular employment in the second experiment because they feel bad about going on public assistance and thereby imposing an externality on others. The implication is that it is also important to take into account the fairness concerns of potential participants, in addition to concerns of taxpayers, when predicting the impact on an institution such as workfare. The result is relevant for the literature on welfare non-participation, supporting the view that non-participation arises partly

12 There were 5 sessions in the experiment, lasting on average 90 minutes, for a total of 84 subjects. On average subjects earned about 16 Euros. Subjects were students at University of Bonn. 
from some form of (internalized) social stigma associated with free riding (see Besley and Coate, 1992).

In summary, these experiments provide insights into some of the important issues surrounding workfare. First, they demonstrate the incentive effects of workfare. The work requirement shifts individual labor supply curves downward, consistent with economic theory. Second, the results on political acceptability show strong support for workfare, and challenge the notion that workfare is necessarily unfair, showing conditions under which fairness concerns reinforce self-interested motives for supporting workfare. Finally, the fairness concerns of potential participants are also relevant for predicting the impact of the institution. Answering these questions involved using experimental techniques to elicit individual supply curves, something which is not possible in the field, and exploiting the possibility to study voting behavior in a controlled environment.

\section{Conclusion}

Experiments are a powerful tool for studying labor market institutions. Perhaps the most important advantage is the ability to implement truly exogenous institutional change, in order to make clear causal inferences. Other advantages include knowledge of the theoretical equilibrium in the market, precise measurement of key aggregate outcomes, such as efficiency and distribution of rents, and the ability to observe important variables, such as reservation wages and worker effort levels, which are never observable in the field. Experiments can also show the impact of institutions at a greater level of detail than is possible in the field, down to the level of changes in contract terms, and changes in the strategic interaction of individual workers and firms within an employment relationship. It is also possible to use experiments to test institutions that do not yet exist, at relatively low cost. Importantly, there are also limitations to experiments, which make them a complement rather than a substitute for field data. However, experiments have yet to be fully exploited as a technique for studying labor institutions. 


\section{References}

Autor, D., Donoghue, J., and Schwab, S. (2004): “The Costs of Wrongful Discharge Laws", Technical Report, MIT.

Besley, T. and Case, A. (2000): "Unnatural Experiments? Estimating the Incidence of Endogenous Policies", The Economic Journal, 110(467), F672-F694.

Besley, T. and Coate, S. (1992): "Understanding Welfare Stigma: Taxpayer Resentment and Statistical Discrimination”, Journal of Public Economics, 48, 165 -183.

Blount, S. (1995): "When Social Outcomes Aren't Fair: The Effect of Causal Attributions on Preferences", Organizational Behavior and Human Decision Process 63, 131-144.

Brandts, J. and Charness, G. (2004): "Do Labour Market Conditions Affect Gift Exchange? Some Experimental Evidence”, Economic Journal 114, 2004, 684708.

Brown, M., Falk, A. and Fehr, E. (2004): "Relational Contracts and the Nature of Long-Term Relations", Econometrica, 72, 747-781.

Card, D. (1992): "Do Minimum Wages reduce Employment? A Case Study of California", 1987-89. Industrial and Labor Relations Review 46(1), 38-54.

Card, D., Katz, L. and Krueger A. (1994): "Comment on 'Employment Effects of Minimum and Sub-minimum Wages: Panel Data on State Minimum Laws", Industrial and Labor Relations Review 47(3): 487-497.

Card, D. and Krueger, A. (1994), "Minimum Wages and Employment: A Case Study of the Fast-Food Industry in New Jersey and Pennsylvania", American Economic Review 84 (4), 772-793.

Card, D. and Krueger, A. (1995): "Myth and Measurement, The new Economics of the minimum Wage", Princeton University Press, Princeton, New Jersey.

Card, D. and Krueger, A. (2000): "A Case Study of the Fast Food Industry in New Jersey and Pennsylvania - Reply", American Economic Review 90(5), 13971420.

Epstein, R. (1984): "In Defense of the Contract at Will", The University of Chicago Law Review, 51(947), 947-982.

Falk, A., Fehr, E. and Zehnder, C. (forthcoming): "The Behavioral Effects of Minimum Wages", forthcoming in The Quarterly Journal of Economics.

Falk, A., Fehr, E. and Fischbacher U. (2003): "On the Nature of Fair Behavior", Economic Inquiry 41(1), 20-26.

Falk, A., Huffman, D., and MacLeod, B. (2006): "EPL and Labor Market Efficiency", IZA Working Paper.

Falk, A., Huffman, D. and Mierendorff, K. (2006) "Incentive Effects and Political Acceptability of Workfare," IZA Working Paper.

Katz, L. and Krueger, A. (1991): „The Effects of the New Minimum Wage in a LowWage labor Market“". Proceedings of the Forty-Third Annual Meetings. Masison, Wis.: Industrial Realtions Research Association, 254-265.

Katz, L. and Krueger, A. (1992): "The Effect of the Minimum Wage on the Fast Food Industry", Industrial and Labor Relations Review, 46(1), 6-21.

Kugler, A. and Saint-Paul, G. (2000) "Hiring and Firing Costs, Adverse Selection and the Persistence of Unemployment," XXX. 
MacLeod, B. (2005): "Regulation or Markets? The Case of Employment Contracts", CESifo Economic Studies 51(1), 1-46.

Neumark, D. and Wascher, W. (1992: "Evidence on Employment Effects of Minimum and Sub-minimum Wage: Panel Data on State Minimum Laws," Industrial and Labor Relations Review 46(1), 55-81.

Neumark, D. and Wascher, W. (2000): "Minimum Wages and Employment: A Case Study of the Fast-Food Industry in New Jersey and Pennsylvania: Comment", American Economic Review 90(5), 1362-96

OECD (1999) Employment Outlook, Paris, France: OECD.

Schlicht, E. (1998): "On Custom in the Economy", Oxford: Clarendon Press.

Zajac, E. (1995): "Political Economy of Fairness", Cambridge, Mass.: The MIT Press. 


\section{Figures}

Figure 1: Histogram of wages in the presence of a minimum wage (black bars) and without minimum wage (grey bars) ${ }^{13}$

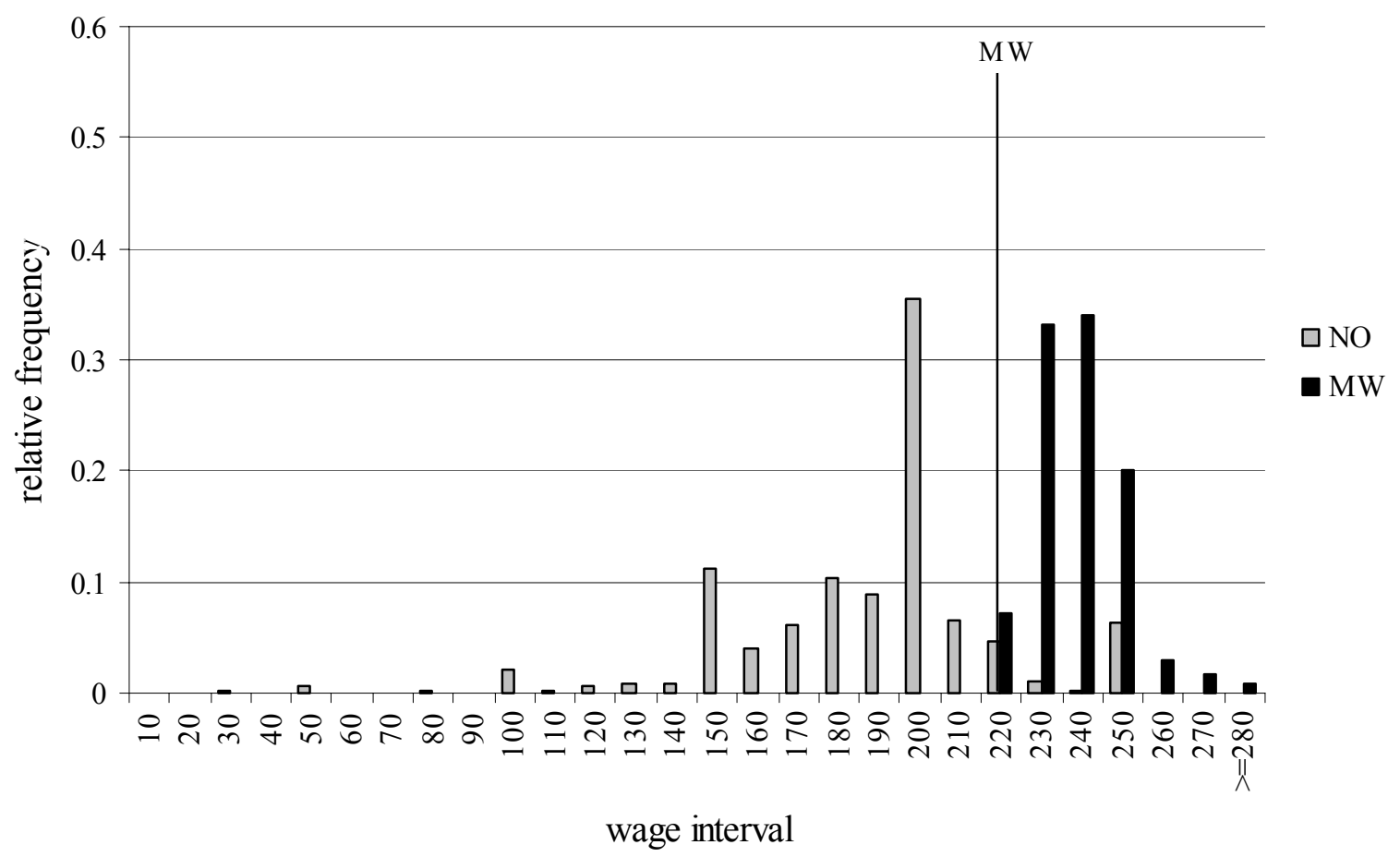

Figure 2: Histogram of reservation wages in the presence of a minimum wage (black bars) and without minimum wage (grey bars)

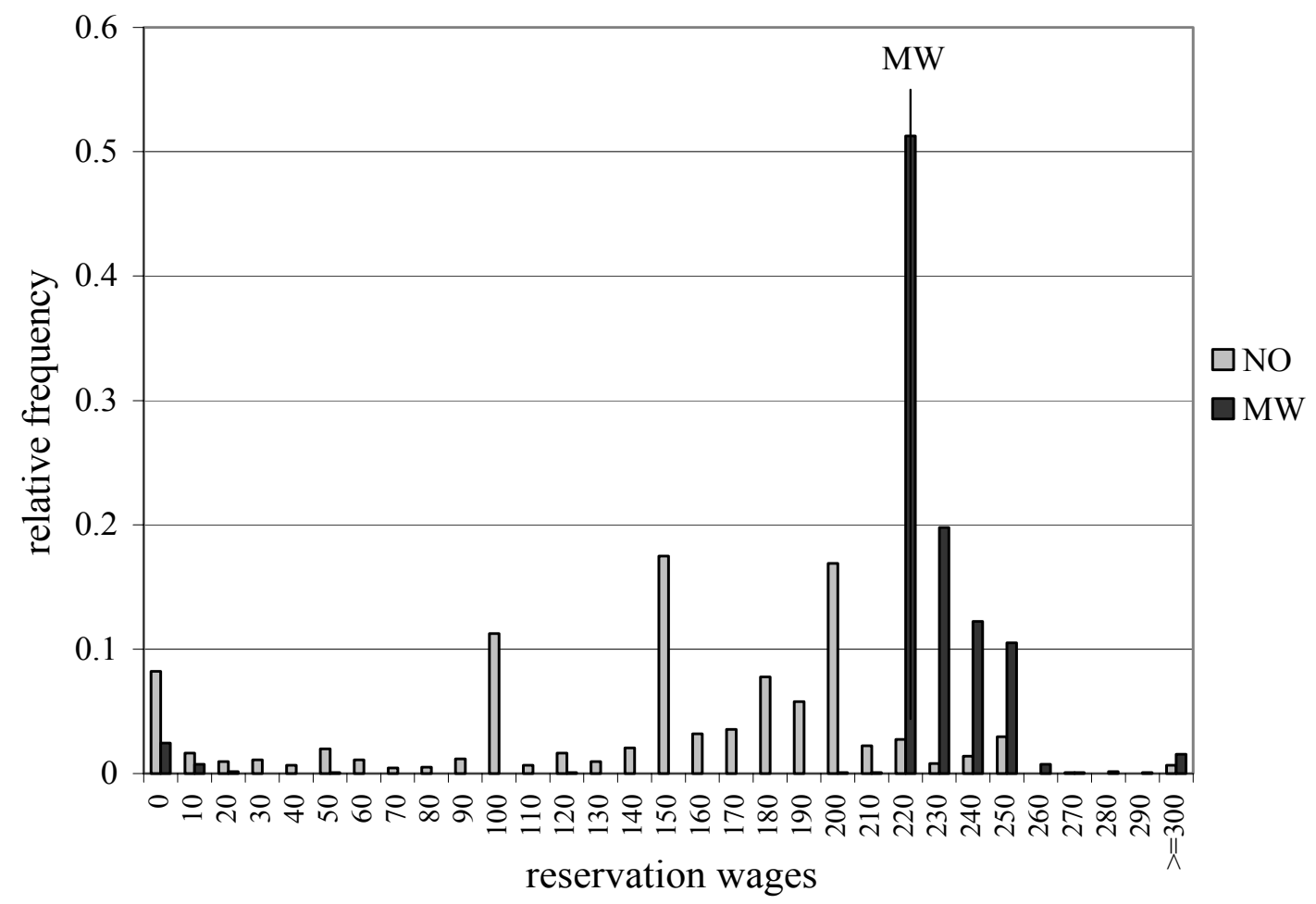

${ }^{13}$ Figures 1, 2 and 3 are taken from Falk et al. (forthcoming). 
Figure 3: Average wages of employed workers when a minimum wage is introduced (grey line) and when it is removed (black line)

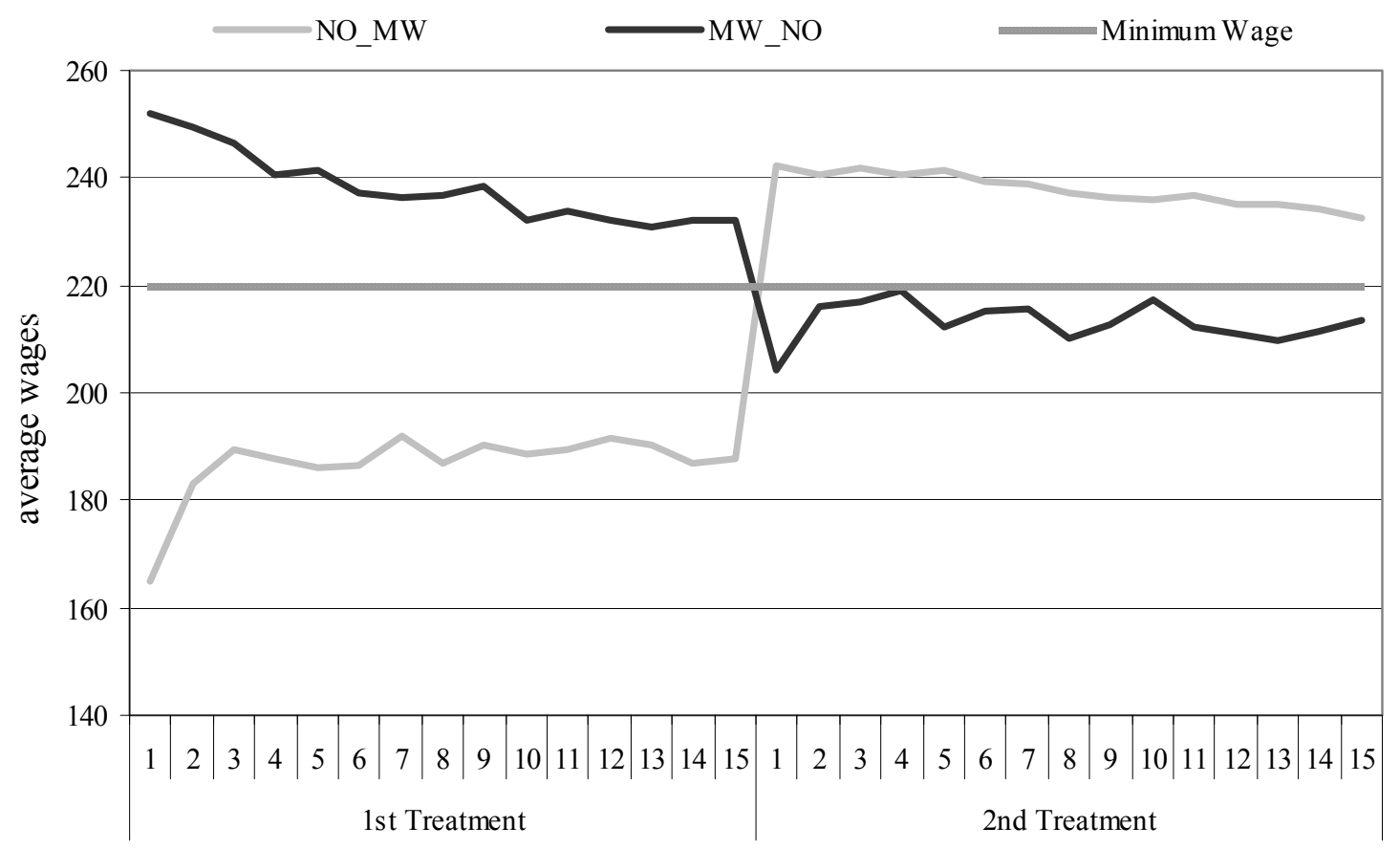

Figure 4: Effort levels (efficiency) in long-term relationships (length $>2$ periods), where either party can end the relationship (Non-EPL), or only workers can end the relationship (EPL)

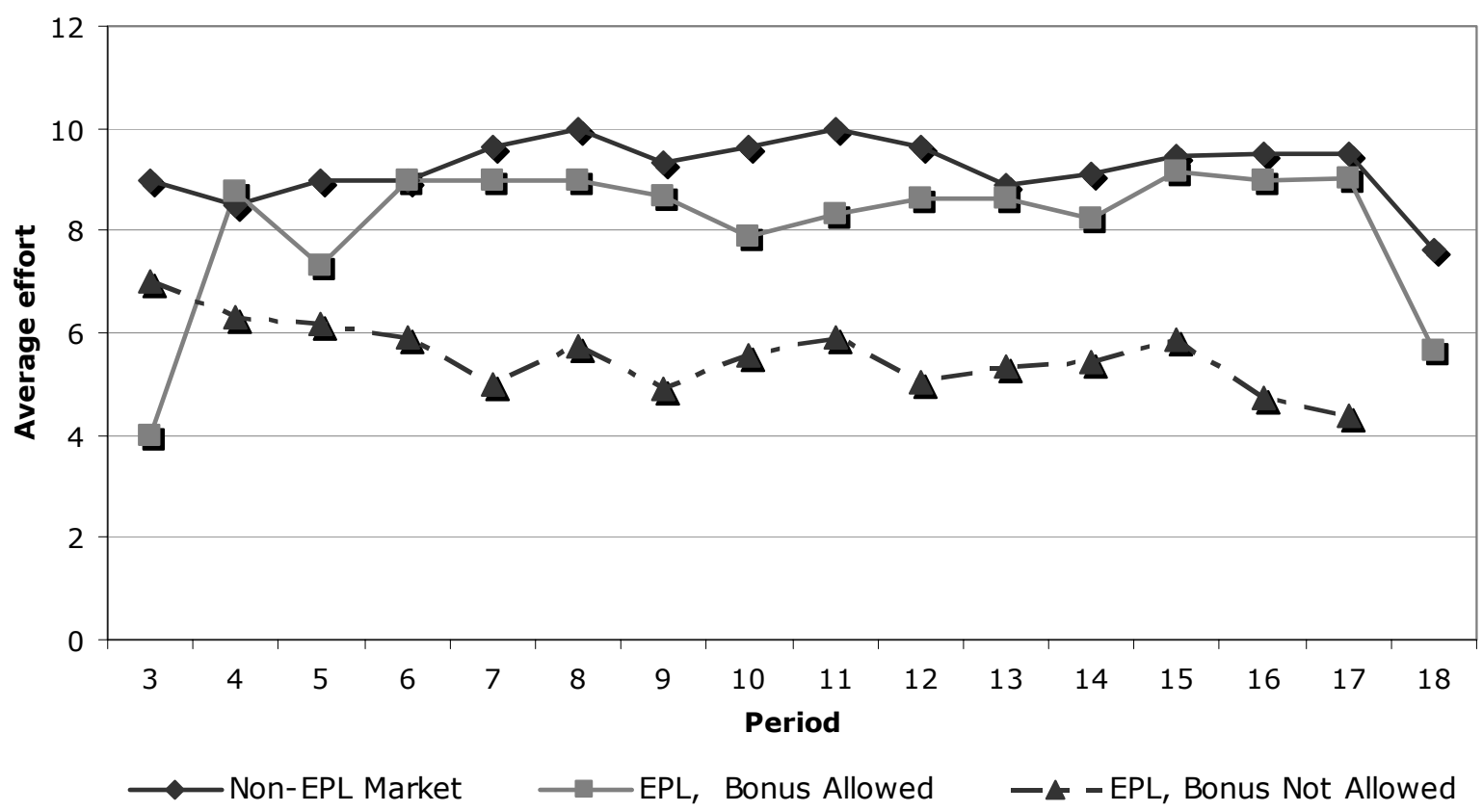


Figure 5: Labor supply curves for the average subject, depending on whether the outside option (4 Euros) involved a work requirement (9 sheets) or no work requirement (0 sheets)

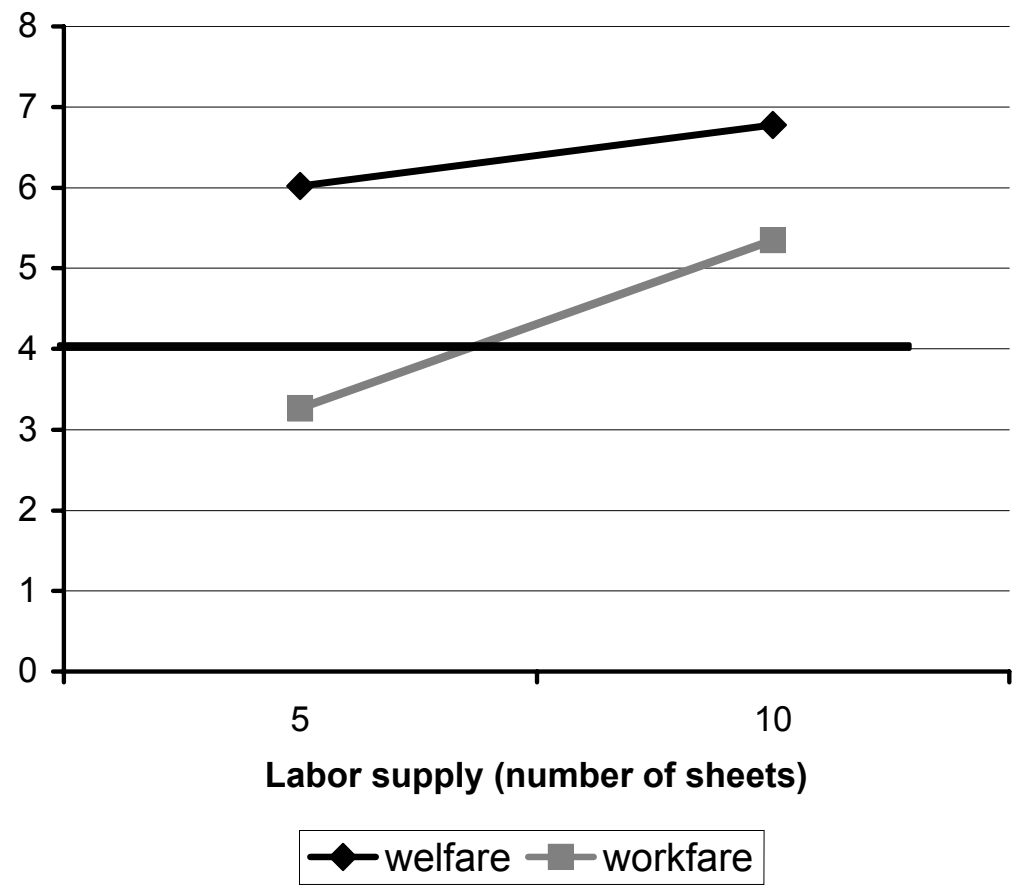

Figure 6: Motives behind voting for workfare, based on categorizing open-ended responses.

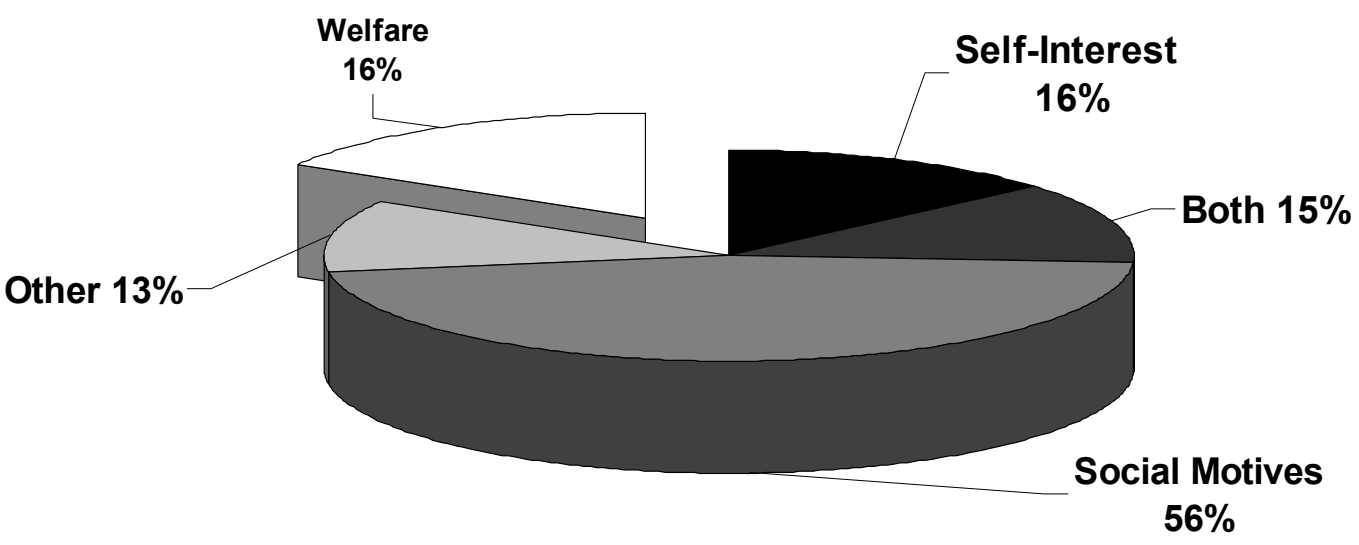

Notes: Subjects are categorized as self-interested if they mentioned only the motive of encouraging recipients to choose regular employment, thereby reducing the tax burden. Those categorized as having social motives mentioned exclusively terms such as fairness, or desire to punish free riders. The remaining subjects mention both self-interested and social motives, or some other motive. 